\title{
Is Numérairology the Future of Monetary Economics?
}

\author{
Unbundling Numéraire and Medium of Exchange \\ through a Virtual Currency and a Shadow Exchange Rate
}

\author{
Willem H. Buiter
}

Published online: 3 May 2007

(C) Springer Science + Business Media, LLC 2007

\begin{abstract}
The paper discusses some fundamental problems in monetary economics associated with the determination and role of the numéraire. The issues are introduced by formalising a proposal, attributed to Eisler, to remove the zero lower bound on nominal interest rates by unbundling the numéraire and medium of exchange/means of payment functions of money. The monetary authorities manage the exchange rate between the numéraire ('sterling') and the means of payment ('drachma'). The short nominal interest rate on sterling bonds can then be used to target stability for the sterling price level. The paper puts question marks behind two key bits of conventional wisdom in contemporary monetary economics. The first is the assumption that the monetary authorities define and determine the numéraire used in private transactions. The second is the proposition that price stability in terms of that numéraire is the appropriate objective of monetary policy. The paper also discusses the merits of the next step following the decoupling of the numeraire from the currency: doing away with currency altogether-the cashless economy. Because the unit of account plays such a central role in New-Keynesian models with nominal rigidities, monetary economics needs to devote more attention to numérairology - the study of the individual and collective choice processes that govern the adoption of a unit of account and its role in economic behaviour.
\end{abstract}

(CWillem H. Buiter 2004-2007.

W. H. Buiter $(\bowtie)$

European Institute, London School of Economics and Political Science,

Universiteit van Amsterdam, NBER and CEPR,

Houghton Street, London WC2A 2AE, UK

e-mail: w.buiter@lse.ac.uk, willembuiter@btinternet.com

URL: http://www.nber.org/wwbuiter/ 
Keywords Zero lower bound • Cashless economy • Price level determinacy • Optimal inflation

JEL Classification E3 E4 E5 E6

\section{Introduction}

In his famous lectures on monetary theory "The Two Triads," Sir John Hicks tried to establish a mapping between the three classical functions of money-means of payment or medium of exchange, store of value and unit of account or numéraire, and the three Keynesian motives for holding money: the transactions motive, the speculative motive and the precautionary motive (Hicks 1967). ${ }^{1}$ The mapping was never completed: the role of money as the numéraire or unit of account remained an orphan. This should not surprise us. The role of the numéraire is one of the least researched and least well understood topics in economics. Consider the following key questions: why and when does it matter what real, financial or imaginary object provides the unit that serves as the numéraire? How is the numéraire (or how are the numéraires) determined or chosen in both barter and monetary economies? Is there a reason for the common but not universal empirical association, in systems with central bank fiat money, of the numéraire and the currency issued by the central bank? Is it surprising that, historically, even in non-fiat money systems, the unit of account has tended to be a commonly used medium of exchange? From within the canon of conventional neoclassical economics, including New Classical and New Keynesian macroeconomics, these questions have not been answered satisfactorily, if at all. Yet in both New Classical and New Keynesian macroeconomics the numéraire plays a crucial role. In both approaches, the maintained assumption that fiat money issued by the central bank (currency) is the numéraire, combined with the assumption that the nominal interest rate on currency is constrained to equal zero, sets a zero floor under the nominal interest rate, that is, the interest rate on instruments denominated in terms of the numéraire. The further assumption that there is a non-zero real demand for currency (sometimes derived from quasi-primitive restrictions on the ability to trade real goods for real goods), means that the nominal interest rate (the interest rate in terms of the numéraire) will, in general, be welfare-relevant. All this applies even when there are no nominal price or wage rigidities.

Even with flexible prices it matters what the numéraire is. If the numéraire were bread, for instance, it would be the bakers rather than the central bank that would determine the rate of inflation, assuming they could bake with

\footnotetext{
${ }^{1}$ Hicks did not consider a fourth function of money found in part of the literature, that of being the 'standard of deferred payment.' As I have never been able to determine what this expression means, the 'standard of deferred payment' will be ignored in what follows.
} 
sufficient speed and flexibility to set the own rate of interest on bread. If in addition money wages or prices were sticky in terms of the bread numéraire, the bakers' guild would have a non-trivial monetary stabilisation policy role. The welfare significance of the numéraire when there are nominal wage or price rigidities survives even in a cashless economy, interpreted here as in Woodford (2003) as the limit of an economy in which central bank currency serves as both means of payment and numéraire, as the demand for currency as a means of payment goes to zero.

The fact that the choice of numéraire has implications for the existence of a liquidity trap would not be of practical interest if the liquidity trap were a theoretical curiosum. There can be little doubt that the liquidity trap was perceived in this way for much if not most of the second half of the 20th century. But no longer. Means and methods for removing the zero floor under the nominal interest rate became more than intellectual curiosa when the Bank of Japan's Discount rate fell to effectively zero in September 2001, a level at which it stood until July 2006. ${ }^{2}$ When the Federal Funds rate target of the Federal Reserve fell to $1.00 \%$ in July 2003 there was a non-negligible risk that the zero lower bound could become a binding constraint on the ability to conduct conventional expansionary monetary policy in the US. Similar concerns were expressed when the ECB's policy rate was cut to $2.00 \%$ in June 2003. Clearly, the urgency to find a way to remove or bypass the zero lower bound has diminished since then, although even at the time of writing (January 2007), the Bank of Japan's policy rate stands only at $0.25 \%$.

The potential problem of the zero lower bound becoming a binding constraint on the conduct of expansionary monetary policy has not disappeared, however. Central Banks throughout the world are committed to the pursuit of price stability, often (though not always, as the case of the US demonstrates) through the adoption and pursuit of a low and stable target for the rate of inflation. ${ }^{3}$ With the world-wide decline in long-run risk-free real interest rates, the pursuit of a low rate of inflation is likely to imply a pattern of, on average, low nominal interest rates. This creates a non-negligible risk that the economy could be impacted by a contractionary shock so severe, that even cutting short nominal interest rates to zero would not represent an adequate monetary policy response. This motivates continued study of alternative mechanisms for setting negative nominal interest rates. The modalities for setting negative nominal interest rates in turn highlight the importance of the extent to which the numéraire function can be unbundled from the means of payment/medium of exchange function. It goes without saying that for something to serve as a medium of exchange and means of payment, it will have to be willingly held between transactions and therefore will have to be a store of value. The key

\footnotetext{
${ }^{2}$ October 2004.

${ }^{3}$ The ECB does not admit to an inflation target, but deems a rate of inflation for the HICP index of less than but close to $2 \%$ per annum consistent with the pursuit of price stability in the medium term - an inflation target that dare not speak its name.
} 
(un)bundling therefore is between on the one hand the numéraire and on the other hand the store of value that serves as means of payment and medium of exchange. ${ }^{4}$

In a comment on Buiter and Panigirtzoglou's (2003) paper on implementing negative nominal interest rates by imposing a carry tax on currency, Professor Davies (2004) points to an interesting alternative mechanism for removing the zero lower bound on nominal interests rates. This mechanism, which Davies attributes to Eisler (1932), does not require the administratively costly, cumbersome and intrusive payment of negative interest rates on currency. Instead it involves the unbundling of the medium of exchange/means of payment function of currency, sterling, say, from its numéraire/unit of account role.

The zero lower bound is associated with the means of payment/medium of exchange role of cash: the bearer bond property of currency makes it difficult to pay interest (positive or negative) on currency. ${ }^{5}$ Instead, in the Eisler economy envisaged by Davies, the authorities abolish sterling as a medium of exchange/means of payment by retiring all sterling currency. Sterling continues to be the numéraire in key private transactions (especially wage settlements and domestic price contracts for goods and services) and the authorities use the short sterling nominal interest rate, without a zero lower bound, to pursue a sterling inflation or sterling price level target. A new currency, the drachma, say, is introduced to serve as the medium of exchange/means of payment in lieu of sterling. Drachma currency, like sterling currency before it was abolished, has a zero nominal interest rate. Both drachma-denominated and sterlingdenominated interest-bearing bonds are issued freely by the authorities. The authorities control and set the nominal interest rate on sterling bonds and the exchange rates (spot and forward, current and future) between drachma and sterling. Even with the interest rate on drachma bonds subject to a zero floor set by the zero interest rate on drachma currency, the interest rate on sterling bonds can be negative if the authorities make a credible commitment to appreciate the sterling-drachma exchange rate.

This paper argues that Davies's proposal contains two potential weaknesses. The first is his assumption that the monetary authorities determine the unit of account, or, more precisely, choose the object(s), real or financial, some

\footnotetext{
${ }^{4}$ For the purposes of this paper, the distinction between the means of payment function (where payment is defined as final settlement of a claim) and the medium of exchange function does not matter.

${ }^{5}$ In modern developed economies, the medium of exchange/means of payment role of currency applies only to a small subset of all transactions-legitimate small scale retail payments and transactions in the grey, black and underground economies. The vast majority of transactions in financial claims, real assets and in currently produced goods and services are not effected through the exchange of currency or settled in currency.
} 
quantity of which serve as the unit of account. ${ }^{6}$ The second is his assumption that it is the behaviour of the price level in terms of that unit of account that matters for economic welfare, or more specifically, that the authorities should pursue price stability (in principle a zero rate of inflation going forward, in practice a low rate of inflation for some real world price index) in terms of that numéraire. The plausibility of both assumptions is questionable. This matters not just in the Eisler universe, which does have a means of payment/medium of exchange (currency, for short), although it does not assign the unit of account/numéraire role to the currency, but also in a world without currency, in a cashless economy. One approach to the numéraire in a cashless economy is to view it as disembodied, abstract numéraire or virtual currency, phlogiston, say. ${ }^{7}$ In that case the authorities cannot set the interest rate in terms of the numéraire. The alternative approach, adopted in this paper, following Woodford (2003), is to define a unit of the numéraire as a unit of some fiat interest-bearing financial instrument issued by the government. In the Eisler economy and in its cashless special case, a unit of the sterling numéraire would be a unit of the short sterling bond-or a financial instrument that is a perfect substitute for the short sterling bond, e.g. commercial bank reserves with the central bank.

The determination of the numéraire and its significance is a much-neglected issue in monetary economics. The great monetary economists of previous generations distinguished carefully between what one of them, Patinkin, called "the abstract unit of account" and the actual, physical (and today also digital), medium of exchange. ${ }^{8}$ The abstract unit of account "...serves only for purposes of computation and record keeping. This unit has no physical existence;" (Patinkin 1965, p. 15). Patinkin refers to prices in terms of the abstract unit of account as accounting prices and prices in terms of the medium of exchange, as money prices. In what follows, accounting prices will also be identified with contracting prices and invoicing prices.

\footnotetext{
${ }^{6}$ Careful scholars in the field of monetary economics have long made the point that it makes no sense to say that money serves as a (or the) unit of account, ... since money is a tangible material not a unit of measurement (McCallum 1989, p. 17, fn. 1). Correct usage would be to say ...that the medium of account is the good some quantity of which serves as the unit of account (i.e. is used as the base for quoted prices) (McCallum 1989, p. 17, fn. 1). Niehans (1978), p. 118, fn 1. makes the same point: "Money is here called a medium and not, as customary, a unit of account because, clearly, money itself is not a unit, but the good whose unit is used as the unit of account."

${ }^{7}$ To emphasize the disassociation between the pure, disembodied numéraire or virtual money and the embodied physical currency of old, I chose, in a different context, phlogiston to be the unit of account or numéraire (Buiter 2002). According to a theory, advanced by J. J. Becher late in the 17 th century and extended and popularized by G. E. Stahl, in all flammable materials there is present phlogiston, a substance without color, odor, taste, or weight that is given off in burning. The phlogiston theory received strong and wide support throughout a large part of the 18th century until it was refuted by the work of A. L. Lavoisier (see The Columbia Electronic Encyclopedia 2003)

${ }^{8}$ For an object to serve as medium of exchange/means of payment it must of course also be a store of value.
} 
Theoretical studies of 'cashless' economies have become something of a growth industry (see e.g. Woodford 2003, and the literature cited there). Nominal rigidities (that is, price and/or wage rigidities in terms of the numérairerigid accounting and contracting prices) play a central role in the New Keynesian literature (see e.g. Clarida et al. 2001; Woodford 2003; Golosov and Lucas 2003). It is therefore appropriate to issue a reminder about the complete absence of deep structural microfoundations of the determination of the numéraire, how it emerges (or is selected) and how it matters for economic behaviour.

In this paper I formalise Davies's proposal and discuss some of the wider implications of the emergence of numérairology - the microfoundations of monetary economics without money. Among the central questions the new cashless monetary economics, like the old monetary economics with money, must address are the following. (1) How is the numéraire determined? Who or what chooses the numéraire or how does it emerge spontaneously from the trading and exchange interactions of purposefully acting but not necessarily unboundedly rational private agents? (2) What determines whether the numéraire be a pure abstract unit of account (like phlogiston), a financial instrument with a means of payment/medium of exchange function, a financial instrument without any special means of payment/medium of exchange function, or a real good or service valued intrinsically as a consumer good or as a productive input? (3) What determines whether there is just one numéraire or more than one? (4) Even if there is only one numéraire, can the government set a short nominal interest rate in terms of that numéraire, that is, can there be 'monetary policy' (defined as nominal interest rate policy) in a cashless economy? (5) Under what conditions is the general price level determinate in a cashless economy? This paper argues that the answer to questions (4) and (5) are simple, but that the questions to answers (1), (2) and (3) are difficult. Existing answers to question (1) are found to be wanting.

\section{Implementing negative nominal interest rates à la Gesell or à la Eisler}

\subsection{The benchmark sterling economy}

The benchmark is the sterling economy. Sterling is the only currency (means of payment/medium of exchange, cash) and the only numéraire. Currency is a liability of the central bank with a risk-free nominal rate of interest $i_{t+1, t}^{M}$. There also are risk-free sterling-denominated non-monetary financial instruments (sterling bonds) with a risk-free nominal sterling interest rate $i_{t+1, t}$. The consumer's stochastic real interest factor between periods $t_{0}$ and $t_{1}$ is $\prod_{k=t_{0}+1}^{t_{1}}\left(1+r_{k, k-1}\right), t_{1}>t_{0}$, where $r_{k, k-1}$ is the one-period real consumption interest rate between periods $k-1$ and $k$. I use the discrete time version of the simple model in Buiter and Panigirtzoglou (2001, 2003)(a closed endowment economy with a representative infinite lived private household with rational expectations and a New Keynesian price Phillips curve), to illustrate a much 
more general point. ${ }^{9}$ The expectation operator conditional on information available in period $t$ is $E_{t}$ and $\operatorname{Cov}_{t}$ is the conditional covariance. Real household consumption in period $t$ is $C_{t}$, the constant level of real period- $t$ government consumption is $G$, actual period- $t$ output is $Y_{t}$, the (constant) natural output level or level of capacity output (the level of output that would prevail with perfect price flexibility) is $\bar{Y}$, the risk-free real consumption interest rate (at market prices) between periods $t_{0}$ and $t_{1}$ is $\tilde{r}_{t_{1}, t_{0}}$, and the sterling inflation rate for consumer prices is $\tilde{\pi}_{t_{1}, t_{0}} \equiv\left(\tilde{P}_{t_{1}} / \tilde{P}_{t_{0}}\right)-1$, where $\tilde{P}_{t}$ is the period $t$ sterling general consumer price level. ${ }^{10}$ The nominal stock of sterling currency at the end of period $t$ is $M_{t}$ and $m_{t} \equiv M_{t} / \tilde{P}_{t}$ is the real stock of sterling currency. The period- $t$ sterling producer price level is $P_{t}$ and the inflation rate of sterling producer prices is $\pi_{t_{1}, t_{0}}=\left(P_{t_{1}} / P_{t_{0}}\right)-1$. The core inflation rate between periods $t_{0}$ and $t_{1}$ is $\omega_{t_{1}, t_{0}}$. It is the component of inflation that is subject to behavioural nominal rigidities. I also define $y \equiv \ln Y$ and $\bar{y} \equiv \ln \bar{Y}$. The period $t$ indirect tax rate is $\tau_{t}$ so $\tilde{P}_{t} \equiv\left(1+\tau_{t}\right) P_{t}$. For $t \geq 0$, the sterling economy is described by Eqs. 1-10:

$$
\begin{gathered}
C_{t}^{-1}=\frac{1}{1+\rho}\left(1+i_{t+1, t}\right) E_{t}\left(\left(1+\tilde{\pi}_{t, t+1}\right) C_{t+1}^{-1}\right)=\frac{1}{1+\rho}\left(1+\tilde{r}_{t+1, t}\right) E_{t} C_{t+1}^{-1}, \\
\rho>0 ; C \geq 0 \\
y_{t}=\ln \left(C_{t}+G\right)
\end{gathered}
$$

Either

$$
y_{t}=\bar{y}
$$

or

$$
\begin{aligned}
\pi_{t, t-1}-\omega_{t, t-1} \approx \alpha\left(y_{t}-\bar{y}\right)+\lambda E_{t}\left(\pi_{t+1, t}-\omega_{t+1, t}\right) . \\
0 \leq G<e^{\bar{y}} ; 1 \geq \lambda \geq 0 ; \alpha \geq 0 \\
\tilde{\pi}_{t, t-1} \approx \pi_{t, t-1}+\tau_{t}-\tau_{t-1} \\
i_{t+1, t}=\rho+E_{t} \tilde{\pi}_{t+1, t}+\zeta\left(E_{t} \tilde{\pi}_{t+1, t}-\widehat{\tilde{\pi}}\right), \\
\quad \text { if } \rho+E_{t} \tilde{\pi}_{t+1, t}+\zeta\left(E_{t} \tilde{\pi}_{t+1, t}-\widehat{\tilde{\pi}}\right) \geq i_{t+1, t}^{M} \\
=i_{t+1, t}^{M} \text { if } \rho+E_{t} \tilde{\pi}_{t+1, t}+\zeta\left(E_{t} \tilde{\pi}_{t+1, t}-\widehat{\tilde{\pi}}\right)<i_{t+1, t}^{M} \\
\zeta>0
\end{aligned}
$$

\footnotetext{
${ }^{9}$ The household decision problem and the derivation of the price setting rule are a simple special case of the New-Keynesian model analysed at length in such standard works as Woodford (2003). For simplicity I assume that the period utility function is additively separable in the logarithms of consumption, leisure and real money balances. A detailed derivation is available from the author on request. A fully worked-out model with all the properties assigned to the simple model of the present paper can be found in Buiter (2006).

${ }^{10}$ Note that $\left(1+\tilde{r}_{t, t-1}\right)^{-1}=E_{t-1}\left(1+r_{t, t-1}\right)^{-1}$ where the expectation is taken over all possible states.
} 


$$
\begin{gathered}
1+\tilde{r}_{t+1, t}=\left(1+i_{t+1, t}\right)\left(1+E_{t} \tilde{\pi}_{t, t+1}+\frac{\operatorname{Cov}_{t}\left(\tilde{\pi}_{t, t+1}, C_{t+1}^{-1}\right)}{E_{t} C_{t+1}^{-1}}\right) \\
m_{t} \equiv \frac{M_{t}}{\tilde{P}_{t}}=\eta\left(\frac{1+i_{t+1, t}}{i_{t+1, t}-i_{t+1, t}^{M}}\right) C_{t} \\
\eta \geq 0 ; i \geq i^{M} ; M \geq 0 ; \quad \tilde{P} \geq 0 \\
E_{0} \lim _{t \rightarrow \infty} \prod_{j=0}^{t}\left(\frac{1}{1+r_{j+1, j}}\right)\left(1+i_{t+1, t}^{M}\right) \frac{M_{t}}{\tilde{P}_{t+1}}=0 \\
M_{-1}=\bar{M}_{-1} \\
\tilde{P}_{-1}=\overline{\tilde{P}}_{-1}
\end{gathered}
$$

Equation 1 contains two key consumption Euler equations. ${ }^{11}$ Equation 2 states that actual output equals the sum of private and public consumption. Equation 3, output equals capacity output, represents the output market clearing condition when prices are fully flexible. Equation 4 is a log-linear approximation at the deterministic steady state of the New-Keynesian Phillips curve, based on Calvo's 1983 model of staggered overlapping nominal price contracts (see also Taylor 1980; Buiter and Jewitt 1981; Buiter and Miller 1985, for similar models). Qualitatively it captures all key aggregate features of the version of Calvo's pricing model expounded in Woodford (2003), although it cannot capture the relative price variability of that disaggregated model. The variable $\omega_{t, t-1}$ represents the behaviour of the constrained price setters of the Calvo model in period $t$, that is, the behaviour of those agents $j$ which cannot freely set their price in period $t$ and instead update the logarithm of their price of the previous period, $p_{t-1}(j)$, say, using the indexation rule $p_{t}(j)=\omega_{t, t-1}+$ $p_{t-1}(j)$. Core inflation is the name given to the ad-hoc, behavioural indexation factor $\omega_{t, t-1}$. An example would be the one-period lagged indexation rule proposed by Woodford (2003), which can be written as

$$
\omega_{t, t-1}=\gamma \pi_{t-1, t-2}
$$

This indexation rule is partial when $0<\gamma<1$. Calvo's original model can be interpreted as the special case of Eq. 11 when $\gamma=0$. In this version of the model, the rate of inflation is non-predetermined (flexible) even though the price level is predetermined (sticky). Full one-period-lagged indexation is the special case of Eq. 11 when $\gamma=1$, that is,

$$
\omega_{t, t-1}=\pi_{t-1, t-2} \text {. }
$$

With this indexation rule, the actual and natural levels of output will be the same for any constant rate of inflation.

\footnotetext{
${ }^{11}$ The period utility function is assumed to be logarithmic in consumption. The pure rate of time preference is $\rho$.
} 
Full current indexation with complete contemporaneous information would produce the following indexation function:

$$
\omega_{t, t-1}=\pi_{t, t-1} .
$$

With this indexation function, all inflation inertia vanishes and actual output always equals its natural level.

An example of full current indexation with partial contemporaneous information would be:

$$
\omega_{t, t-1}=E_{t-1} \pi_{t, t-1} .
$$

With Eq. 14, actual output equals its natural level whenever the rate of inflation is fully anticipated.

Equation 5 defines the relationship between consumer prices and producer prices.

Equation $6 \mathrm{~b}$ is a simplified Taylor rule for the short nominal interest rate on sterling bonds; $\widehat{\tilde{\pi}}$ can be interpreted as the target rate of inflation of consumer prices. ${ }^{12}$ The Taylor rule only determines the short nominal interest rate if this is greater than or equal to the nominal interest rate on sterling currency. If application of the Taylor rule would put the nominal interest rate on sterling bonds below the nominal interest rate on sterling currency, the actual nominal interest rate on sterling bonds equals that on sterling currency. When in the discussion that follows, optimal policy is considered, the Taylor rule (6b) is overridden when its application cannot support the social optimum.

Equation 7 links the risk-free nominal and risk-free real sterling interest rates through the expected inflation rate of the sterling general price level and an inflation risk premium. The demand for real sterling currency is proportional to real private consumption and inversely proportional to the pecuniary opportunity cost of holding sterling currency. ${ }^{13}$ The cashless economy is the special case where $\eta=0$. The boundary condition (9) is obtained from the Standard Transversality Condition of the household optimisation problem, which implies that the present value of terminal household financial wealth (monetary and non-monetary) is zero, and from the government's intertemporal budget constraint, that the present discounted value of the government's terminal stock of non-monetary debt is non-positive. When the government follows a fiscal-financial-monetary programme for which its intertemporal budget constraint holds with equality, the boundary condition (9) follows. The asymmetry between the private and government solvency constraints is due to the assumption that government-issued fiat base money is viewed as an asset by the holder (the households) but not, in the long run, as a liability by the issuer

\footnotetext{
${ }^{12}$ It makes no substantive difference to any of the issues discussed in the paper whether the Taylor rule targets the rate of inflation of the consumer price level or of the producer price level.

${ }^{13}$ This follows from a money-in-the-utility-function model of money demand when the period utility function of the representative household is assumed to be additively separable in the logarithm of consumption and the logarithm of real money balances.
} 
(the government). This irredeemability or inconvertibility of base money is a primitive assumption (see Buiter 2003, 2005; Buiter and Sibert 2007).

Treating the own rate of interest on currency as exogenous, the instrument of the monetary authorities is either the nominal quantity of sterling currency or the nominal interest rate on short sterling bonds. ${ }^{14}$ Descriptive realism makes $i_{t+1, t}$ the monetary instrument in the sterling economy. The simplified Taylor rule in Eq. $6 \mathrm{~b}$ is a reasonably descriptively realistic example of a nominal interest rate rule, but plays no essential role in the argument.

In Buiter (2006) I show that, in an 'upmarket' version of the simple model used here, ${ }^{15}$ for both the flexible price version and for a version with Calvo's staggered overlapping price setting mechanism, the social optimum is achieved when two conditions are satisfied. First, the pecuniary opportunity cost of holding cash is zero-the optimal quantity of money (OQM) rule of Bailey (1956) and Friedman (1969) given in Eq. 15 applies and there are no shoeleather costs. Second, actual output equals its natural level (Eq. 16). ${ }^{16}$ The latter condition is, of course, automatically satisfied in the flexible price model.

$$
\begin{aligned}
i_{t+1, t} & =i_{t+1, t}^{M} \\
y_{t} & =\bar{y} .
\end{aligned}
$$

With Calvo price contracts, the second optimality condition, Eq. 16, is satisfied (for any indexation function) if and only if actual producer price inflation equals core producer price inflation:

$$
\pi_{t, t-1}=\omega_{t, t-1} .
$$

\footnotetext{
${ }^{14}$ Base money includes commercial bank sterling balances held with the central bank as well as sterling currency (and coint). Such balances held in electronic ledgers are not 'bearer bonds.' The Central bank knows the identity of each account holder and the balance outstanding. Paying interest on commercial bank balances held with the central bank is easy and effectively costless. Formally, such balances are either ignored in what follows, or they are perfect substitutes for sterling bonds but not for currency (in retail transactions etc.).

${ }^{15}$ Households have Dixit-Stiglitz preferences over a bundle of differentiated consumption goods. Each household's labour endowment can either be consumed as leisure, used to produce a unique single variety of the consumption good or used to manage cash-balances. Consumer goods are subject to a flexible cash-in-advance constraint. Consumer goods prices are determined by monopolistically competitive price setters constrained by Calvo-style staggered, overlapping nominal price contracts and simple price indexation rules for the constrained price setters. Fully flexible prices are a limiting case of the Calvo-style contract. The fiscal authorities can use production subsidies to address inefficiencies due to monopoly power, and an indirect tax (VAT or sales tax) to drive a wedge between the consumer price level and the producer price level. The simpler model used here permits me to reproduce all the key insights of this richer, more detailed and more complex model, provided the New Keynesian Phillips curves (Eq. 4 for the Sterling economy and Eq. 33 for the Eisler economy) are taken on faith as acceptable log-linear approximations to the true underlying non-linear relationships.

${ }^{16}$ I assume for simplicity that the natural rate level of output is efficient. The Calvo model has monopolistic competition in the output market, so the natural level of output is too low. I assume that such 'steady-state real distortions' have been corrected through non-lump sum taxes or subsidies or through regulation. None of the key results of the paper depend on the efficiency of the natural rate.
} 
Equality of actual and core producer price inflation is automatically satisfied if the constrained price setters use full current indexation with complete contemporaneous information (Eq. 13). For any other core inflation process, it requires that the actual producer price inflation rate validate the core inflation rate. If the nominal interest rate on money, $i_{t+1, t}^{M}$, can be set freely, then this validation can be achieved even if the nominal interest rate on bonds $i_{t+1, t}$ is governed by the Taylor rule (6b) and (6b). Appropriate manipulation of the indirect tax rate $\tau_{t}$ (see Eq. 5) can translate the consumer price inflation rate $\tilde{\pi}_{t, t-1}$ determined from the consumer Euler equation (1) into a producer price inflation rate $\pi_{t, t-1}$ that validates the core inflation rate $\omega_{t, t-1}$. Alternatively, the actual producer price inflation rate can be made to validate the core inflation rate even with a constant indirect tax rate, if the Taylor rule (6a) and (6b) is dropped and the nominal interest rate on bonds is dedicated to equating actual (consumer and producer price) inflation to core inflation period-byperiod. If the nominal interest rate on cash is constrained to equal zero, the OQM rule can only be implemented with a zero nominal interest rate on bonds, and the Taylor rule would have to be jettisoned to support the social optimum. The indirect tax rate then would have to be managed to equate the actual and the core inflation rates of producer prices. When prices are fully flexible, nominal equilibrium values, $P, \tilde{P}$ and $M$ are indeterminate for any interest rate rule that makes $i$ and $i^{M}$ a function of real variables only. ${ }^{17}$ With the New-Keynesian Phillips curve, the price level is always determinate, through history, that is, through the initial condition for the general price level, except in the case of full contemporaneous indexation (given by Eq. 13), which eliminates all traces of nominal rigidity.

\subsection{Gesell's carry tax on currency}

If, as is the case in practice, the own rate of interest on sterling currency is zero, the risk-free nominal interest rate on sterling bonds, $i_{t+1, t}$, cannot be lower than zero: ${ }^{18}$

$$
i_{t+1, t} \geq 0 .
$$

If the effective pursuit of the policy objectives of the monetary authorities (assumed to be a stable sterling price level or a low sterling rate of inflation) were to call for negative nominal interest rates on sterling bonds, policy would be impeded by the zero lower bound on the nominal interest rate. Paying interest on currency is difficult because currency is a negotiable bearer bond. The identity of the bearer (the owner) is not known to the issuer. Buiter and Panigirtzoglou $(2001,2003)$ revived a proposal going back at least to Gesell (1916) for paying negative interest on currency by requiring that currency

\footnotetext{
${ }^{17}$ This includes exogenous or 'open-loop' sequences for the two nominal interest rates.

${ }^{18}$ For simplicity we ignore differential carry costs for currency and bonds.
} 
be stamped periodically in order to remain a legal financial instrument (see also Fisher 1933; Goodfriend 2000). The bearer of the currency could be taxed (thus receiving a negative interest rate on currency) at the time the currency was stamped. Suitable fines or other penalties would be required to induce the bearer of the currency to come forward to pay this carry tax on currency. The non-negativity constraint on the risk-free nominal interest rate on sterling bonds would be replaced by the constraint that the risk-free nominal interest rate on sterling bonds cannot be lower than the interest rate on sterling currency, $i_{t+1, t}^{M}$ :

$$
i_{t+1, t} \geq i_{t+1, t}^{M} .
$$

With this carry tax, the interest rate on currency can be set at any negative (or positive) level. Collecting it would, however, be cumbersome, costly and intrusive. A lower cost implementation of negative interest rates on currency than those associated with Gesell's proposal for stamped currency would be welcome.

\subsection{Eisler's unbundling of numéraire and currency}

Davies's proposal, which he attributes to Eisler (1932), is simple. ${ }^{19}$ The authorities unbundle the means of payment/medium of exchange role of money from its numéraire or unit of account function. All sterling notes and coins are retired, so sterling currency no longer exists in physical form (or even in disembodied, virtual form as balances held in an electronic ledger). The sterling money demand function (8) is no longer part of the household decision rules. The constraint that the nominal interest rate on sterling bonds cannot be below the interest rate on sterling currency has become moot.

The authorities introduce a new currency, drachma say, which takes on the means of payment and medium of exchange role formerly performed by sterling currency. The interest rate on the new drachma currency is zero, for the same reason the interest rate on the old sterling currency was zero. Davies assumes that sterling remains the unit of account for the wage and price contracts that matter, and that it is the sterling price level whose behaviour (stability, low inflation) the authorities continue to target. For that reason, the fact that the nominal interest rate on sterling bonds is no longer subject to the zero lower bound is what matters, rather than the fact that the nominal interest rate on drachma bonds is now subject to the zero lower bound.

The assumption that sterling remains the unit of account is reflected in the retention of the sterling Phillips curve in Eq. 4 as the relevant pricing equation in the Eisler economy, following the disappearance of sterling currency. There continue to be nominal rigidities in the sterling price level and, if core inflation depends on lagged actual inflation, also in the sterling rate of inflation. The

\footnotetext{
${ }^{19}$ Further information on Eisler and 'virtual currencies' can be found in Einaudi (1953); Gaitskell (1969) and Boyle (2002).
} 
sterling price level remains a predetermined state variable. The assumption that the authorities continue to target the sterling price level or sterling rate of inflation is reflected in the retention of the Taylor rule (6b) for the short sterling interest rate. This is a feedback rule from the sterling rate of inflation, which includes a sterling inflation target $\widehat{\tilde{\pi}}$.

The nominal stock of drachma currency is $M^{*}$, the drachma general consumer price level is $\tilde{P}^{*}$, the risk-free nominal interest rate on drachma bonds is $i^{*}$ and the nominal interest rate on drachma currency is $i^{*^{M}}$. The consumer's real rate of return on nominal drachma bonds is $r^{*}$. There is a demand for real drachma currency from the private sector, $m^{*}$, given in Eq. 20 which has the same functional form as the demand for real sterling balances in Eq. 8:

$$
\begin{aligned}
& m_{t}^{*} \equiv \frac{M_{t}^{*}}{\tilde{P}_{t}^{*}}=\eta\left(\frac{1+i_{t+1, t}^{*}}{i_{t+1, t}^{*}-i_{t+1, t}^{*^{M}}}\right) C_{t} . \\
& M^{*} \geq 0 ; \quad \tilde{P}^{*} \geq 0 ; i^{*} \geq i^{*^{M}}
\end{aligned}
$$

The boundary condition for the household becomes:

$$
E_{0} \lim _{t \rightarrow \infty} \prod_{j=0}^{t}\left(\frac{1}{1+r_{j+1, j}^{*}}\right) \frac{\left(1+i_{t+1, t}^{*^{M}}\right) M_{t}^{*}}{\tilde{P}_{t+1}^{*}}=0
$$

and the initial conditions become:

$$
\begin{aligned}
M_{-1}^{*} & =\bar{M}_{-1}^{*} \\
\tilde{P}_{-1}^{*} & =\bar{P}_{-1}^{*}
\end{aligned}
$$

The risk-free one-period real consumption interest rate in the drachma economy, $\tilde{r}^{*}$ satisfies

$$
1+\tilde{r}_{t+1, t}^{*}=\left(1+i_{t+1, t}^{*}\right)\left(1+E_{t} \tilde{\pi}_{t, t+1}^{*}+\frac{\operatorname{Cov}_{t}\left(\tilde{\pi}_{t, t+1}^{*}, C_{t+1}^{-1}\right)}{E_{t} C_{t+1}^{-1}}\right)
$$

where $\tilde{\pi}_{t_{1}, t_{0}}^{*} \equiv\left(\tilde{P}_{t_{1}}^{*} / \tilde{P}_{t_{0}}^{*}\right)-1$ is the drachma consumer price inflation rate between periods $t_{0}$ and $t_{1} \cdot{ }^{20}$ The drachma producer price inflation rate is $\pi_{t_{1}, t_{0}}^{*} \equiv\left(P_{t_{1}}^{*} / P_{t_{0}}^{*}\right)-1$ and $\tilde{P}_{t}^{*}=\left(1+\tau_{t}\right) P_{t}^{*}$.

Since, by assumption, the nominal interest rate on drachma currency in the Eisler economy, is zero, $i_{t+1, t}^{* M}=0$, the risk-free nominal interest rate on drachma bonds is subject to the zero lower bound:

$$
i_{t+1, t}^{*} \geq 0 .
$$

${ }^{20} E_{t}\left(1+r_{t+1, t}^{*}\right)^{-1}=\left(1+\tilde{r}_{t+1, t}^{*}\right)^{-1}$. 
However, Eq. 6b, the lower bound on the sterling nominal interest rate, no longer applies in the Eisler economy, since there no longer is any sterling currency earning the rate $i^{M}$. The government issues both sterling-denominated and drachma-denominated bonds. If drachma bonds and sterling bonds can both be issued and held by the private sector, their risk-adjusted returns should be equalised. Since both $i$ and $i^{*}$ are risk-free interest rates, they are linked by covered interest parity (CIP). Let $S_{t}$ be the period- $t$ spot exchange rate between sterling and drachma (defined as the number of drachma per unit of sterling) and $F_{t+1, t}$ the period $t$ one-period forward exchange rate. Then

$$
1+i_{t+1, t}=\frac{S_{t}}{F_{t+1, t}}\left(1+i_{t+1, t}^{*}\right)
$$

The authorities have three instruments: the nominal interest rate on sterling bonds and the spot and forward exchange rates between sterling and drachma. Given these three, the risk-free nominal interest rate on drachma bonds is determined as

$$
\begin{aligned}
1+i_{t+1, t}^{*} & =\frac{F_{t+1}}{S_{t}}\left(1+i_{t+1, t}\right) \text { if } \frac{F_{t+1, t}}{S_{t}}\left(1+i_{t+1, t}\right) \geq 1 \\
& =1 \text { if } \frac{F_{t+1}}{S_{t}}\left(1+i_{t+1, t}\right)<1
\end{aligned}
$$

Let $\varphi_{t_{1}, t_{0}} \equiv \frac{F_{t_{1}, t_{0}}}{S_{t_{0}}}$ be the one plus the proportional forward premium on sterling vis-à-vis drachma (the sterling forward premium factor). A negative nominal interest rate on sterling bonds can be implemented even if the nominal interest rate on drachma bonds is constrained by the zero lower bound on drachma nominal interest rates. If, for instance, $i_{t+1, t}^{*}=0$, then $i_{t+1, t}=\frac{1-\varphi_{t+1, t}}{\varphi_{t+1, t}}$. By setting the forward price of sterling above its spot price (by 'appreciating' sterling relative to the drachma), that is, by setting $\varphi_{t+1, t}>1$, the nominal interest rate on sterling bonds can always be set by the authorities at any desired negative level, even when the nominal interest rate on drachma bonds is bounded from below by zero.

The forward rate cannot, of course, be set independently of the (expected) path of future spot rates. Let $\sigma_{t_{1}, t_{0}} \equiv S_{t_{1}} / S_{t_{0}}$ be one plus the proportional rate of appreciation of sterling in terms of drachma (the sterling appreciation factor). In efficient financial markets, the following relationship holds between the sterling interest rate, the drachma interest rate and current and future spot exchange rates when the period utility function is logarithmic in consumption:

$$
\frac{1+i_{t+1, t}}{1+i_{t+1, t}^{*}}=E_{t} \sigma_{t, t+1}+\frac{\operatorname{Cov}_{t}\left(C_{t+1}^{-1} \tilde{\pi}_{t, t+1}, \sigma_{t, t+1}\right)}{E_{t}\left(C_{t+1}^{-1} \tilde{\pi}_{t, t+1}\right)} .
$$

If the conditional covariance in Eq. 26 is zero, say because there is no subjective uncertainty about the future nominal spot exchange rate, the expected 
future spot exchange rate equals the current forward rate, as in Eq. 27, that is, uncovered interest parity (UIP) prevails, as in Eq. $28 .^{21}$

$$
\begin{gathered}
F_{t+1, t}=E_{t} S_{t+1} \\
\frac{1+i_{t+1, t}}{1+i_{t+1, t}^{*}}=E_{t} \sigma_{t, t+1} .
\end{gathered}
$$

Commodity arbitrage ensures that the sterling price of each good or service equals the drachma price of that good or service, multiplied by the price of drachma in terms of sterling. Since this 'law of one price' (LOP) holds for each good and service produced and consumed in the domestic economy, it also holds for the aggregate sterling and drachma price levels: ${ }^{22}$

$$
\begin{aligned}
& P_{t} S_{t}=P_{t}^{*} \\
& \tilde{P}_{t} S_{t}=\tilde{P}_{t}^{*}
\end{aligned}
$$

or

$$
\begin{aligned}
\pi_{t+1, t} \sigma_{t+1, t} & =\pi_{t+1, t}^{*} \\
\tilde{\pi}_{t+1, t} \sigma_{t+1, t} & =\tilde{\pi}_{t+1, t}^{*}
\end{aligned}
$$

If follows that in the Eisler economy, the real return on nominal sterling bonds is equal to the real return on nominal drachma bonds if UIP prevails, which will be the case if the behaviour of the nominal exchange rate is certain, in which case Eq. 31 holds:

$$
1+r_{t+1, t} \equiv\left(1+i_{t+1, t}\right) \tilde{\pi}_{t, t+1}=\frac{S_{t+1}}{F_{t+1, t}}\left(1+i_{t+1, t}^{*}\right) \tilde{\pi}_{t, t+1}^{*} \equiv \frac{S_{t+1}}{F_{t+1, t}}\left(1+r_{t+1, t}^{*}\right) .
$$

Note that Eq. 1 is still an appropriate characterisation of optimal consumption behaviour although the following Euler equation also holds:

$$
C_{t}^{-1}=\beta\left(1+i_{t+1, t}^{*}\right) E_{t}\left(\left(1+\tilde{\pi}_{t, t+1}^{*}\right) C_{t+1}^{-1}\right)=\beta\left(1+\tilde{r}_{t+1, t}\right) E_{t} C_{t+1}^{-1} .
$$

Not surprisingly, the capacity to achieve, through a fully credible appreciation of sterling in terms of drachma, lower sterling nominal interest rates than drachma nominal interest rates does not translate, because of the Law of one Price, into a capacity to achieve lower real rates of return on nominal sterling bonds than on nominal drachma bonds. Sterling appreciation lowers both the sterling nominal interest rate relative to the drachma nominal interest rates

\footnotetext{
${ }^{21}$ The same applies if investors are risk-neutral and currency appreciation and sterling inflation rates are uncorrelated.

${ }^{22} \mathrm{We}$ are pricing, in a given country, a given bundle of goods and services in two currencies. Familiar trade theory reasons for departures from the law of one price (transportation costs, taxes, market segmentation, price discrimination) and from purchasing power parity (non-traded goods, different commodity baskets) therefore don't apply here.
} 
and the sterling rate of inflation relative to the drachma rate of inflation. When the sterling appreciation rate is certain, the two effects cancel each other out exactly.

However, the fact that in the Eisler economy, if the nominal exchange rate is certain, the real rate of return on nominal sterling bonds is the same as the real rate of return on nominal drachma bonds, does not mean that real interest rates, including the risk-free real rate of interest in the Eisler economy, $\tilde{r}^{*}$, is the same as it would have been had the lower bound on the sterling nominal interest rate not been removed. Equations 1, 4, 6a and 7 apply unchanged in the Eisler economy, but the lower bound on the nominal interest rate on sterling bonds, Eq. $6 \mathrm{~b}$ has been eliminated and the range of $i$ now is the entire real line. The behaviour of the risk-free real interest rate $\tilde{r}^{*}$ is also affected and altered by the removal of the lower bound on the nominal interest rate on sterling bonds. This is immediately obvious if we assume that $\alpha=0$, but it is also true for positive values of $\alpha$.

\section{The three key building blocks of the Eisler economy}

Whether or not Davies's proposal is of practical interest rests on one technical assumption, which turns out not to be problematic, and on two key behavioural assumptions, both of which are by no means self-evident. The technical assumption is that the monetary authorities can fix the relative spot and forward prices of sterling and the drachma even though sterling currency no longer exists. The first key behavioural assumption is that the monetary authorities determine what the (unique) unit of account in the economy is. Sterling remains the (unique) unit of account even though the drachma is now the medium of exchange and means of payment. The second key behavioural assumption is that it is the behaviour of the price level in terms of this unit of account (sterling) or the rate of inflation of this price level that matters for economic welfare and that it therefore is the sterling price level/rate of inflation that is or should be targeted by the monetary authorities.

3.1 How do the authorities set the sterling-drachma exchange rate in the Eisler economy?

In the Eisler economy, sterling appears to be an abstract (disembodied) numéraire - a virtual currency. As there is no sterling currency, earning a sterling rate of interest of $i_{t+1, t}$ can therefore not mean that for every unit of sterling currency given up in period $t$ one gets back $1+i_{t+1, t}$ units of currency in period $t+1$. In normal parlance, the sterling-drachma spot exchange rate refers to the spot exchange rate of a unit of sterling currency for a unit of drachma currency. This definition cannot apply in the Eisler economy, since sterling currency no longer exists. To peg the relative price of two currencies (as for any two commodities) the price fixing agent has to be willing and able to supply or absorb any amount demanded or supplied by the other market

를 Springer 
participants at that price. Since sterling currency no longer exists, fixing the relative price of sterling currency and drachma currency is not possible in the Eisler economy: one cannot price phlogiston.

This turns out not to be a substantive objection, however. The solution can be found in Woodford's (2003) characterisation of a cashless economy. In such an economy, currency (of any kind) no longer exists but the government still issues a financial instrument that can be interpreted as the other (noncurrency) component of the monetary base: commercial bank balances held with the central bank or bank reserves for short. Unlike currency, reserves are not negotiable bearer bonds: the identity of their owner is known to the issuer (the central bank). It is therefore trivial to pay interest on reserves at a positive or a negative rate. The unit of account in terms of which these reserves are denominated is the same as that of the defunct currency-sterling in the Eisler model. The authorities issue or purchase this sterling-denominated financial instrument-reserves - on demand at the spot and forward prices of sterling in terms of drachma currency, $S_{t}$ and $F_{t+1, t}$, that they set. The sterlingdrachma spot exchange rate is therefore the spot exchange rate of a unit of sterling reserves for a unit of drachma currency. The further assumption is then made that sterling bank reserves and sterling one-period bonds are perfect substitutes in private portfolios (offer the same pay-offs in every state of nature) and therefore that they both earn a period return of $i_{t+1, t}$. Thus, a unit of sterling also means (is) a unit of the sterling bond. Since a unit of drachma currency buys one unit of drachma bonds, the sterling-drachma spot exchange rate is also the exchange rate of a unit of sterling reserves for a unit of drachma bonds.

In the Eisler economy, as in the cashless economy (the special case of both the benchmark sterling economy and the Eisler economy where $\eta=0$ ), it therefore cannot be true to say that sterling is a pure abstract numéraire or virtual currency if the authorities are able to set the sterling rate of interest. There has to be something, a financial instrument called sterling, whose rate of return can be fixed by the government because the government defines what sterling is and can issue or retire any amount of this instrument at any time, offering any rate of return in wishes in terms of sterling. In the Eisler economy as in the cashless economy, sterling is the sterling bond, or a perfect substitute for it. Woodford's interest-bearing commercial bank reserves with the central bank, the non-currency component of the monetary base, which are perfect substitutes for one-period sterling bonds, are the obvious candidate. You can therefore price phlogiston, and set the phlogiston rate of interest, if you define phlogiston to be the unit in terms of which some financial instrument of the authorities is denominated.

\subsection{Who or what determines the numéraire?}

Davies assumes that the government (the monetary authorities) determines what the unique unit of account in the economy is. The monetary authorities could withdraw all existing cash while maintaining the 
existing monetary unit of account; (emphasis added). How would they do this? As pointed out by Davies (2004), there is no doubt that the government (including the monetary authority) can do much to encourage the use of a particular numéraire for invoicing and recording transactions and for denominating contracts. The government can choose units of account (or a single unit of account) in terms of which one or more of its own financial liabilities are defined. It can declare certain financial instruments (including some of its own liabilities) to be legal tender, and it can decide what should be the unit of account that defines the financial instruments that have legal tender status. The government can legislate that financial contracts between private parties are not enforceable in the courts unless they are denominated in terms of a particular unit of account. ${ }^{23}$ It can choose the units of account used to define tax liabilities. The government may even be able to determine the unit of account in a wide range of contracts involving itself, other agents of the state and the private sector. It is certainly possible that the government's use of a particular unit of account to define its financial liabilities and its insistence on the use of that unit of account in (most of) its transactions with other parties, make is likely that private parties would use that same unit of account in exchanges and contracts among themselves.

Possible, but not necessary or inevitable. Davies points out, correctly and with historical evidence to back it up, that the unit of account used (or used most widely) in a society need not be the unit of denomination of whatever financial instruments are used as means of payment and medium of exchange. Everyone is familiar with the Guinea, which was neither the official unit of account used by the UK monetary authorities in their transactions, nor a medium of exchange/means of payment after 1813, but continued to be used as the numéraire in auction houses and expensive and pretentious shops until decimalisation in $1971 .^{24}$ The Guinea example contradicts both the view that the private unit of account (that is the unit of account used in transactions between private parties) is the official monetary unit of account, and the view that the numéraire is whatever the medium of exchange/means of payment is. However, it is true that most historical examples from the fiat government money era bundle in a single object/instrument the government's unit of account, the unit of account used in contracts between private parties and the means of payment/medium of exchange for most retail transactions.

\footnotetext{
${ }^{23}$ This would, presumably, not apply to contracts between private domestic parties and foreign residents.

${ }^{24}$ The guinea came into existence in 1666 under King Charles II. The last guinea was issued in 1813, but the guinea continued to be used as a monetary unit of account until decimalisation in 1971. When they were first issued, one Guinea exchanged for one Pound (or 20 shillings). The relative price of the Pound Sterling and the Guinea fluctuated widely, reflecting changes in the relative price of silver and gold, until the de-facto demonetisation of silver in the UK in 1817. At that time, the Pound Sterling, the UK's monetary unit, was worth 20 shillings (or 100 new pence). The Guinea was worth 21 shillings (or 105 new pence).
} 
Unfortunately, the historical evidence on societies in which the numéraire and means of payment/medium of exchange functions were unbundled, while rich and varied, is anecdotal and patchy. I can only offer a partial sample here.

The historical record of primitive monies, described in Paul Einzig's fascinating book Einzig (1949) contains many examples of the uncoupling of the official numéraire function both from the private numéraire and from the medium of exchange/means of payment function. While the evidence is patchy, there are numerous examples cited by Einzig of the numéraire used in private contracts 'following' the official numé raire rather than the medium of exchange/means of payment. Medieval Iceland had a cattle, a cloth and a fish-standard. The monetary unit known as the kugildi was defined precisely in terms of a standardized cow. ${ }^{25}$ It is doubtful that the kugildi could ever have been extensively used as a medium of exchange. Einzig reports that in documents it was often explicitly stated that "...payment fixed in kugildi was actually to be made in metallic money or in other form" (Einzig 1949, p. 260). Plain home-woven woollen cloth (wadmal) served as a general standard of value (unit of account) throughout the Icelandic medieval period. It was used to determine the amount of wergeld ${ }^{26}$ to be paid and for the valuation of damages. Taxes were fixed in wadmal. Unlike kugildi, wadmal was widely used as a medium of exchange. There was a fixed legal exchange rate between kugildi and wadmal. In the 15th century, dried stockfish appears to have been used widely in Iceland as a unit of account. Einzig expresses doubt as to whether it was widely used as a medium of exchange (Einzig 1949, p. 262), and one can only hope he is right in this. In the case of the wadmal, it is interesting that, while the authorities fixed taxes in terms of wadmal, there was no monetary authority with a monopoly of the supply of wadmal. Every home with a spinning wheel and a hand-loom could become a private mint.

In more recent times, and even in the fiat money era, there are examples that support the view that the unit of account used most widely in a society need not be the official monetary unit used to define (some of) the liabilities of the central bank. In countries with very high inflation or hyperinflation, the unit of account has often been a more stable foreign currency, although the means of payment/medium of exchange for small-scale retail transactions remained the national currency. For instance, the US dollar played that role in Israel during the inflation surge that prompted the successful stabilisation plan of July 1985 and in Peru during the hyperinflation that led to the successful stabilisation package of August 1990. The US dollar was used as the numéraire for posting retail prices, but after a hasty verification of the current exchange rate, retail transactions tended to be settled in shekels, respectively intis or soles.

\footnotetext{
25 "The standard of value was the cow of 3-10 winters. It had to be at least of medium size; it had to have had less than three calves, and it had to be without blemish, horned, and milking" (Einzig 1949, p. 260).

${ }^{26}$ In Europe during the middle ages, wergeld was the compensation to be paid to the heirs of a slain man by the slayer(s) or his (their) kin. In various forms and under different names, similar practices existed worldwide and continue to exist in many countries.
} 
An interesting, albeit short-lived monetary experiment took place in the eleven countries that made up the Eurozone between the date of the official designation of the euro as the new numéraire on January 1, 1999 and the introduction of the physical euro currency around January 1, 2002. ${ }^{27}$ During that 3-year period, the national legacy currencies continued to function as media of exchange and means of payment for cash transactions. Officially, however, the euro was the numéraire from January 1, 1999 on, and the national currencies represented inconvenient non-integer denominations of the euro. In reality, however, the national legacy currencies continued to be used overwhelmingly as the unit of account not just in transactions involving payment with these national legacy currencies, but also in contracts that might be settled using non-cash means of payment. The numéraire in the bulk of private transactions (cash and non-cash) stayed with the means of payment/medium of exchange despite the introduction of the new numéraire, the euro. In practice, until euro currency was introduced and the national legacy currencies lost their legal tender status, the euro was treated as an inconvenient non-integer denomination of the national legacy currencies.

A set of interesting social experiments that may shed some light on who or what determines the numéraire and how this relates to the medium of exchange/means of payment function can be found in the proliferation of LETS money schemes. ${ }^{28}$ These Local Exchange Trading Systems, and similar schemes like ROCS (Robust Complementary Community Currency System) and Time Dollars, build on a venerable tradition going back at least 70 years. ${ }^{29}$ LETS is a closed mutual credit system. LETS 'money' is issued by participants as mutual credit-each transaction is recorded as a matching credit and debit in the two participants' accounts. Credit can be used to acquire in the future a certain range of goods and services from the other participants (account holders) in the system (a very simple example with just a single good is a baby-sitting pool). The interest rate (in terms of the numéraire used to record the debits and credits) is typically zero. The LETS system uses the national currency of the country where it is located as the numéraire, but national currency is not used to settle transactions-there is no currency, only the instantaneous and simultaneous recording of the debit and matching credit. The ROCS system uses an hour of standardised labour time as the unit of account. This is neither the numéraire of the monetary authorities nor a currency issued by the monetary authorities or by the ROCS system. It is an example of a cashless (local) exchange and credit system where the numéraire is not the unit of account of the monetary authorities.

\footnotetext{
${ }^{27}$ Greece joined the Eurozone as its twelfth member on 1-1-2001.

${ }^{28} \mathrm{I}$ am indebted to Carol Burgoyne for drawing my attention this phenomenon. See e.g. http:// www.transaction.net/money/lets/.

${ }^{29}$ For instance, the WIR (Wirtschaftsring or Business Circle) founded in Zurich in 1934 built on the example of an even earlier Scandinavian organisation (see http://www.ex.ac. $\mathrm{uk} /$ RDavies/arian/wir.html).
} 
Davies is not alone in asserting without any supporting argument that the monetary authorities determine the private unit of account. Woodford (2003) writes: ... the unit of account in a purely fiat system is defined in terms of the liabilities of the central bank. (Woodford 2003, p. 35, emphasis in the original); and The special feature of central banks, then, is simply that they are entities whose liabilities happen to be used to define the unit of account in a wide range of contracts that other people exchange with one another (Woodford 2003, p. 37). This amounts to a 'legal restrictions' theory of the determination of the numéraire. Even the casual empirical evidence referred to earlier suffices to make the point that the proposition that the monetary authorities determine, as if by fiat, the private unit of account, does not stand up to scrutiny.

What serves as unit of account in private transactions and private contracts and in the mental arithmetic involved in economic calculation and computation is determined by individual choice conditioned by social convention, rooted in culture and history, not by government decree. The unit of account that matters for private decision makers and is used to record transactions among private parties, is decided by them alone. Nothing in the primitive assumptions of conventional (unboundedly rational) optimising economic theory (preferences, information, technology, endowments) implies that the private unit of account - the unit of account used for private calculation and computation and for recording contracts between private parties-be defined in terms of the liabilities of the central bank or in terms of the media of exchange or means of payment widely used in the economy. There is no requirement that it be something that exists either in the physical world or in the world of cyberspace-it could be something purely imaginary like the aforementioned phlogiston. Different private agents within the same polity may use different units of account for invoicing, contracting and mental calculus. This would seem to be an area of research where controlled experiments may offer more hope of insight than reasoning from first principles or studying the uncontrolled one-time experiment called history.

Conventional (unbounded rationality) economics has no theory of the numéraire. To explain at a deep level why the numéraire is one thing rather than another, why the numéraire is so often (although not universally) the means of payment/medium of exchange in everyday retail transactions, why it so often (but again not universally) is the unit of denomination of the central bank's liabilities, and why it matters what the numéraire is, requires the abandonment of unbounded rationality. The fact that sterling is used in the Eisler economy as the unit of account by the monetary authorities may well make it a likely focal point as the numéraire used in private invoices and contracts and for private measurement and calculations. By the same token, the fact that drachma are used as the means of payment/medium of exchange also makes the drachma a natural focal point as the (or a) private numéraire.

The choice of the private unit of account may also be influenced by the way private agents perceive and frame the reality they try to measure and capture with numbers. That the ROCS schemes use standardised units of labour time (SULT) as the unit of account is no doubt influenced by the labour theory of 
value that appears to be part of the mindset of many of the proponents of and participants in this scheme. ${ }^{30}$ It matters because, were wages or prices to be are widely set in terms of SULT, and were there to be 'nominal' rigidity of wage and price contracts in terms of this numéraire, the interest rate in terms of SULT would be the relevant 'monetary policy' instrument if monetary policy aimed to influence the output gap or, in models with disaggregated output or labour markets, the degree of relative price or wage dispersion cased by nominal wage or price rigidities.

The examples cited above show that it is not clear a priori, whether the private numéraire will 'follow the currency' or 'follow the monetary authorities' numéraire' when the unit of account of the monetary authorities is unbundled from the currency. It is not an issue that can be settled a priori by reasoning from first principles, but an empirical matter.

If the unit of account were to 'follow the currency' in the Eisler economy, the sterling Phillips curve (4) and the Taylor rule for the sterling nominal interest rate (6b) and (6b) would become irrelevant. In their place would come a drachma Phillips curve, incorporating rigidity of nominal drachma prices, as in Eq. 33, and a Taylor rule for the drachma nominal interest rate on bonds, incorporating a drachma inflation target, as in Eq. 34a. That the nominal interest rate on drachma bonds is subject to the lower bound set by the interest rate on drachma currency, now becomes a constraint on monetary policy, as is apparent from Eq. 34b. The indexation rules of the constrained price setters (given by Eqs. 11, 12,13 or 14 in the sterling economy) now become indexation rules (not reproduced below) relating individual drachma prices to the past, present or anticipated future aggregate drachma inflation.

$$
\begin{aligned}
\pi_{t, t-1}^{*}-\omega_{t, t-1}^{*}=\alpha\left(y_{t}-\bar{y}\right)+\lambda E_{t}\left(\pi_{t+1, t}^{*}-\omega_{t+1, t}^{*}\right) \\
i_{t+1, t}^{*}=\rho+E_{t} \tilde{\pi}_{t+1, t}^{*}+\zeta\left(E_{t} \tilde{\pi}_{t+1, t}^{*}-\widehat{\tilde{\pi}}^{*}\right), \\
\quad \text { if } \rho+E_{t} \tilde{\pi}_{t+1, t}^{*}+\zeta\left(E_{t} \tilde{\pi}_{t+1, t}^{*}-\widehat{\tilde{\pi}}^{*}\right) \geq i_{t+1, t}^{*} \\
=i_{t+1, t}^{* M} \text { if } \rho+E_{t} \tilde{\pi}_{t+1, t}^{*}+\zeta\left(E_{t} \tilde{\pi}_{t+1, t}^{*}-\widehat{\tilde{\pi}}^{*}\right)<i_{t+1, t}^{* M}
\end{aligned}
$$

If the numéraire 'follows the currency,' the resulting economy is not the Eisler economy (with the drachma as currency and sterling as numéraire) but a pure drachma economy, equivalent in every respect to the original sterling economy, except for the, economically irrelevant (for both nominal and real equilibrium values), change in the name of the currency and numéraire from sterling to drachma.

\footnotetext{
30 " A mindset, in decision science and general systems theory, refers to a set of assumptions, methods and notations that create a powerful incentive to continue to agree with prior conclusions, to use prior tools. It is described as a 'mental inertia,' or 'groupthink,' or 'paradigm' applying to analysis and decision and solutions, and which is hard to escape." From Wikepedia (2004). 
3.3 Should the authorities target the price level in terms of the numéraire?

Assume for the sake of argument that, despite the abolition of sterling currency and the introduction of drachma currency, sterling remains the numéraire and that the sterling nominal price rigidities, reflected in the sterling Phillips curve (4), are unaffected by the change in currency. In this Eisler economy, should the authorities target the sterling price level/inflation rate or the drachma price level/inflation rate? Should they target price stability (a zero rate of inflation going forward) in terms of the numéraire (sterling) or in terms of the currency (drachma)?

In the Eisler economy, the social optimum is achieved when the pecuniary opportunity cost of holding drachma balances equals zero and actual output equals capacity output. This is achieved by equating the nominal interest rates on drachma currency and bonds, as in Eq. 35. With fully flexible sterling prices, the optimal output level is achieved automatically. With Calvo price contracts, actual and capacity output levels are equated by achieving equality between the actual and core inflation rates of sterling producer prices, as in Eqs. 16 and 17 .

$$
i_{t+1, t}^{* M}=i_{t+1, t}^{*}
$$

Assuming that the nominal interest rate on (drachma) currency is zero, the optimal risk-free nominal interest rate on drachma bonds is also equal to zero: $i_{t+1, t}^{*}=0$. That implies a unique rate of drachma consumer price inflation. Consider the simplest stationary example where capacity output and real government spending are constant. It follows that private consumption is constant, $C_{t}=e^{\bar{y}}-G$, and therefore that the risk-free real interest rate is equal to the pure rate of time preference:

$$
\tilde{r}_{t+1, t}=\rho .
$$

The expected rate of inflation of drachma consumer prices equals minus the pure rate of time preference:

$$
E_{t} \tilde{\pi}_{t, t+1}^{*}=-\rho .
$$

When sterling prices are fully flexible, any sequence of sterling producer and consumer price inflation rates is equivalent from the point of view of consumer welfare. With Calvo price contracts, the optimal rate of sterling producer price inflation equals the core rate of producer price inflation, whatever that happens to be:

$$
\pi_{t, t-1}=\omega_{t, t-1} .
$$

With both the sterling nominal interest rate, $i_{t+1, t}$, and the indirect tax rate, $\tau_{t}$, available, the authorities can validate any core inflation process (the sterling interest rate can be set freely despite the optimal drachma nominal interest rate being zero, because the authorities control the exchange rate between sterling and drachma). Unless, fortuitously, the sterling producer price core inflation process happens to yield a zero rate of inflation each period, the 
optimal rate of sterling producer price inflation will not be zero. The optimal rate of sterling producer price inflation need not even be constant. When there is full current indexation with complete contemporaneous information, as in Eq. 13, any sequence of inflation rates for sterling producer prices, including zero, supports the social optimum. The optimal rate of drachma price inflation is, of course, negative, since the time preference rate is positive. With a positive real interest rate a negative drachma consumer price inflation rate is required to achieve a zero nominal interest rate and implement the Bailey-Friedman OQM rule.

In the special case of the cashless economy $(\eta=0)$, the OQM argument for a zero nominal interest rate in terms of the currency (drachma) and the associated negative optimal rate of drachma consumer price inflation ceases to apply. Optimal monetary policy then just involves achieving equality between actual output and capacity output. This is achieved automatically when sterling prices are fully flexible. With Calvo price contracts, the social optimum is again characterised by equality between actual and core sterling producer price inflation.

Not surprisingly, general equilibrium models in which money only exists as a numéraire, yield determinate relative prices and other real equilibrium variables, but an indeterminate price level in terms of the numéraire when all prices are freely flexible. This follows immediately from the nominal indeterminacy of the flexible price level equilibrium when there is currency $(\eta>0)$ but the policy rules for the two nominal interest rates (in terms of the currency) make both of them functions of real variables only. When there is no nominal stock of money, there is no nominal anchor if nominal prices are flexible.

Two approaches at overcoming this 'nominal indeterminacy' have been proposed. The first, the so-called fiscal theory of the price level (see e.g. Cochrane 1998; Woodford 2001), proposed the stock of non-monetary nominal debt as a nominal anchor. It was shown to be a fallacy in Buiter (2002, 2005) and Niepelt (2004). The second approach, of which the New-Keynesian Phillips curve used in this paper is an example, abandons the assumption of perfect nominal price and wage flexibility and assumes that there is rigidity, inertia or stickiness in prices and/or wages in terms of the numéraire. This eliminates the nominal indeterminacy problem. The general price level is determined by history (initial conditions). Equilibrium nominal prices are determinate but unavoidably hysteretic or path-dependent. The inflation rate is determinate and not automatically hysteretic. Uniqueness of the equilibrium inflation rate is less likely in the cashless economy $(\eta=0)$ than in an otherwise identical economy which has a transactions role for government-issued fiat currency $(\eta>0)$. The reason is that in a model with currency, the boundary condition involving the long-run behaviour of the present discounted value of the terminal money stock (see Eq. 9) restricts the set of possible equilibria (see Brock 1974; Buiter and Sibert 2007; Buiter 2005).

The result that optimal monetary policy will implement the Optimal Quantity of Money rule for the drachma inflation rate and will validate sterling 
producer price core inflation, whatever that happens to be, is not robust to two important extensions of the models considered here. The first is the introduction of constraints on the ability of the authorities to impose lumpsum taxes or make lump-sum transfers. With such constraints, seigniorage revenues, that is, the real resources appropriated by the authorities through the issuance of base money, can become a valuable source of revenue for the authorities. Depending on the details of the tax instruments assumed to be available, this may raise the inflation rate associated with the optimal monetary policy for any nominal interest rate on money.

The second is menu costs, that is, the explicit consideration of the real resource costs associated with changing prices or renegotiating price contracts, as in the papers of Caplin and Spulber (1987) and Caplin and Leahy (1991). Such menu costs should be interpreted broadly to include the costs in terms of time, effort and inconvenience of working, computing and calculating with an inconvenient yardstick whose length can vary from period to period. The implications of menu costs for the optimal rate of inflation depend crucially on the details of how menu costs are modeled. It makes a difference whether a real sunk cost is incurred every time a nominal price is changed, or only when a new contract (which may involve indexation) is negotiated. Nominal price changes that are the result of the mechanical implementation of an invariant indexation rule may have lower menu costs than nominal price changes which are the result of bargaining between buyers and sellers or the outcome of an auction. If menu costs are assumed to be particularly important for the goods and services that make up the cost-of-living index, this would drive the optimal inflation rate of the cost of living index closer to zero. If, as seems more plausible, menu costs are especially important for money wages (negotiating and bargaining over wages, whether bilaterally or through organised labour unions and/or employers' associations is costly and time-consuming), a zero rate of money wage inflation would be a natural focus of monetary policy. With positive labour productivity growth, zero wage inflation would imply a negative rate of inflation for the cost of living, consumer and producer price indices.

\section{Conclusion: is numérairology the (only) future of monetary economics?}

There are two fundamental but interesting weaknesses in Davies's analysis, each one of which points to a pervasive key weakness in contemporary monetary theory. The first is the questionable assumption that the government (the monetary authority) determines the numéraire or unit of account in terms of which key private wage and price contracts are denominated, even if the currency is not denominated in terms of that numéraire. The truth is that we have no satisfactory theory of what determines the numéraire in private contracts. The second is the assumption that, assuming the authorities indeed determine the private numéraire, the monetary policy objective should be the stabilisation of the general price level in terms of that numéraire. 
The government is certainly able, in the Eisler economy, to set itself a price level or inflation target defined in terms of the sterling price index and to use the nominal interest rate on sterling bonds, to pursue that target unconstrained by the zero lower bound on the sterling nominal interest rate. The question is, does it make sense, from a welfare point of view, to target the sterling price index in the Eisler economy? This paper demonstrates that, for the class of New Keynesian models under consideration, the answer to this second question is, in general, negative.

Based on these considerations, Eisler's escape route from the zero lower bound on nominal interest rates could well turn out to be a dead end. It raises, however, an important and much-neglected issue in monetary economicsthe determination and significance of the numéraire. Cognitive psychologists may explain why certain units of account are more likely to be used in private transactions and mental arithmetic than others. It is not something the monetary authority decides. It is patently not true that the unit of account in a purely fiat system can simply be defined in terms of one of the liabilities of the central bank. It is a matter of individual choice buttressed by social convention. The monetary authorities can unbundle the means of payment/unit of account function of the fiat currency it issues from the numéraire function as used by the authorities themselves. They cannot unbundle by fiat the means of payment/medium of exchange function and the unit of account function for the economy as a whole.

The Eisler economy separates the medium of exchange/means of payment function of money, which requires the existence of money as a financial instrument, from its role as numéraire. It is but a small intellectual step from this to doing away with the medium of exchange function/means of payment functions of money altogether. This brings us to the cashless economy where short government bonds (or perfect substitutes for them such as bank reserves with the central bank) are the numéraire. The importance of a serious, that is, deep structural, positive and normative theory of the numéraire is underlined by the recent growth of an influential literature for which the numéraire or unit of account (or, strictly speaking) medium of account function is the only primitive one left of the traditional Hicksian triad: means of payment (medium of exchange), store of value and unit of account. The medium of exchange has disappeared. While a pure virtual currency that serves as numéraire does not have to be a store of value itself, there must exist some financial instrument denominated in terms of the virtual currency-a financial instrument that is a store of value-for which the authorities can set the interest rate in terms of that virtual currency, if the authorities are to be able to control the rate of inflation in terms of the numéraire. ${ }^{31}$

Clarida et al. (2001); Woodford (2003); Golosov and Lucas (2003) and many others propose models without a medium of exchange or means of payment

\footnotetext{
${ }^{31}$ Patinkin's abstract unit of account-phlogiston, say -need not be a store of value, but the government must be willing and able to issue phlogiston-denominated financial instruments whose interest rate it can set and that the private sector is willing to hold.
} 
but with a numéraire in terms of which key private contracts (wages and prices) are denominated and with authorities capable of setting the interest rate in terms of that numéraire. A justification offered by (Golosov and Lucas 2003, pp. 12-13) for the omission of a monetary financial instrument is that money can be added to the period utility function without this changing any of the key behavioural properties of the model, provided real money balances enter the period utility function in an additively separable manner. This is clearly not correct as regards the welfare economics of alternative monetary policies. Whenever the demand for real money balances is sensitive to the financial opportunity cost of holding money balances, shoe-leather cost and cash goods/credit goods considerations influence the optimal monetary policy rule, in addition to the nominal price or wage rigidities (due to menu costs or other considerations) that are considered by Golosov and Lucas, and that can cause deviations of actual output or employment from their natural levels as well as suboptimal cross-sectional and time-series distributions of relative prices.

As regards the positive economics of consumption, labour supply and production, we know from a large literature on money-in-the-utility function, money-in-the-shopping function, real cash management, money-in-theproduction function and cash-in-advance models, that alternative monetary policy rules in general support different real equilibria (see e.g. the literature surveyed in Walsh 2000; McCallum and Goodfriend 1987; McCallum 2001). A simple example is the way the boundary condition constraining the present discounted value of the terminal stock of money balances rules out deflationary bubble equilibria in an economy with currency that would be feasible in an otherwise identical cashless economy (see Buiter and Sibert 2007; Buiter 2005). This example of 'money matters' holds even if real money balances enter the period utility function in an additively separable manner (see Buiter 2003, 2005; Buiter and Sibert 2007). The zero lower bound on nominal interest rates also disappears from view when money as a store of value is absent from the model.

Money issuance (seigniorage) provides the government with a source of revenue that can be (and has been) quantitatively significant in many developing countries and emerging markets, even though in advanced industrial countries with well-developed financial and payments systems, its contribution to government revenue is minor. Of course, the excess burden imposed by distortionary taxes cannot be assessed from the amount of revenue it raises. Furthermore, even when the contribution of seigniorage to government revenue is small in normal times, the capacity to use monetary financing, including both the anticipated and the unanticipated inflation taxes on money and on other nominally denominated fixed-rate financial instruments, can have important welfare implications during abnormal times if the government does not have sufficient lump-sum tax instruments and only a restricted set of commodity or income taxes.

Finally, the contemporary fashion for studying the role of money in complete market models deprives central bank (government) fiat liabilities of their 
unique creditworthiness and liquidity properties, which are crucial in times of crises and disorderly markets. ${ }^{32}$ With complete markets there is no default in equilibrium. Disorderly markets therefore will not occur and liquidity is not an interesting property of financial claims, because everything will be equally liquid. In a world with incomplete markets, default can occur in equilibrium. Fear of default can cause illiquidity of otherwise sound financial and real assets. The fact that the central bank is an agent of the state and that the state is the agent with the uniquely deep pockets (through its capacity to tax) means that the creditworthiness and liquidity of central bank liabilities is second to none, indeed unique. The monetary base may well disappear at some time in the not too distant future. One can visualise a world where central bank currency is replaced by various forms of private e-money and where commercial banks do not hold balances with the central bank. However, such a world would no doubt have overdraft facilities, contingent credit lines or other contingent arrangements for banks and other private financial institutions with the central bank, ensuring that central bank liquidity would be available when needed. Monetary economics without money, that is, without the unique fiat liabilities of the central bank or the unique capacity of the central bank (as agent of the state) to create financial instruments of unquestioned creditworthiness and liquidity, in any amount, at little or no notice and at little or no cost, would seem to be, as yet, a bridge too far.

Acknowledgements I would like to thank Carol Burgoyne, Stephen Davies, Anne Sibert and George Tavlas for helpful discussions on the subject matter of this paper.

\section{References}

Bailey MJ (1956) The welfare costs of inflationary finance. J Polit Econ 64(2):93-110

Boyle D (ed) (2002) The money changers: currency reform from Aristotle to e-cash. Earthscan, London

Brock WA (1974) Money and growth: the case of long run perfect foresight. Int Econ Rev 15(3):750-777

Buiter WH (2002) The fiscal theory of the price level: a critique. Econ J 112:459-480

Buiter WH (2003) Helicopter money: irredeemable fiat money and the liquidity trap. NBER Working Paper No. 10163. http://www.nber.org/wbuiter/helinber.pdf

Buiter WH (2006) The elusive welfare economics of price stability as a monetary policy objective: why New Keynesian central bankers should validate core inflation. European Central Bank Working Paper Series No. 609. http://www.nber.org/wwbuiter/oqm.pdf

Buiter WH (2005) New developments in monetary economics: two ghosts, two eccentricities, a fallacy, a mirage and a mythos. In: Royal Economic Society 2004 Hahn lecture, 6 April 2004, Royal Economic Society annual conference, Swansea, UK. Econ J 115(502):C1-C31. http://www.nber.org/ $/$ wbuiter/hahn.pdf

Buiter WH, Jewitt I (1981) Staggered wage setting with real wage relativities: variations on a theme of Taylor. Manch Sch 49:211-28. Reprinted In: Buiter WH (ed) Macroeconomic theory and stabilisation policy. Michigan University Press, Ann Arbour, MA, pp 183-199.

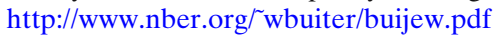

\footnotetext{
${ }^{32}$ See Goodhart (2006) for an eloquent development of this view.
} 
Buiter WH, Miller MH (1985) Costs and benefits of an anti-inflationary policy: questions and issues. In Argy A, Nevile J (eds), Inflation and unemployment: theory, experience and policy making. G. Allen, London, UK, pp 11-38. Reprinted In: Buiter WH (ed) Macroeconomic theory and stabilisation policy. Michigan University Press, Ann Arbour, MA, pp 200-227. http://www.nber.org//wbuiter/buimil.pdf

Buiter WH, Panigirtzoglou N (2001) Liquidity traps: how to avoid them and how to escape them. In: Wim Vanthoor FV and Mooij J (eds) Reflections on economics and econometrics, essays in honour of Martin Fase. De Nederlandsche Bank NV, Amsterdam, pp 13-58

Buiter WH, Panigirtzoglou N (2003) Overcoming the zero bound on nominal interest rates with negative interest on currency: Gesell's solution. Econ J 113:723-746

Buiter WH, Sibert AC (September 2007) Deflationary bubbles. Macroecon Dyn vol. 11, forthcoming. http://www.nber.org/ wbuiter/defbub.pdf

Calvo G (1983) Staggered contracts in a utility-maximizing framework. J Monet Econ 12:383-398

Caplin A, Spulber D (1987) Menu costs and the neutrality of money. Q J Econ 102:703-725

Caplin A, Leahy J (1991) State dependent pricing and the dynamics of money and output. Q J Econ 106:683-708

The Columbia Electronic Encyclopedia (2003) 6th edn. Columbia University Press, New York

Clarida R, Gali J, Gertler M (2001) Optimal monetary policy in open versus closed economies: an integrated approach. Am Econ Rev (Papers and Proceedings) 81(2):248-275

Cochrane JH (1998) A frictionless model of U.S. inflation. In: Bernanke BS, Rotemberg JJ (eds) NBER macroeconomics annual 1998. MIT press, Cambridge MA, pp 323-384

Davies S (2004) Comment on Buiter and Panigirtzoglou. Mimeo, Research Institute for Economics and Business Administration, Kobe University, Japan

Einaudi L (1953) The theory of imaginary money from Charlemagne to the French Revolution. In: Lane FC, Riemersma JC (eds) Enterprise and secular change. G. Allen, New York, pp 229-261

Einzig P (1949) Primitive money in its ethnological, historical and economic aspects. Pergamon, Oxford (2nd edn, 1966)

Eisler R (1932) Stable money: the remedy for the economic world crisis: a programme of financial reconstruction. In: International conference 1933, with a preface by Vickers VC. Search Publishing, London

Fisher I (1933) Stamp scrip. Adelphi, New York

Friedman M (1969) The optimum quantity of money. In Friedman M (ed) The optimum quantity of money and other essays. Adline, Chicago, Chapt 1, pp 1-50

Gaitskell H (1969) Four monetary heretics: Douglas—social credit, Soddy—bank credit, Gesell— free money, Eisler-stable money. In: Pritchard MGL (ed) Introduction. Lyn Christie, Christchurch, New Zealand

Gesell S (1916) Die Natuerliche Wirtschaftsordnung. Rudolf Zitzman Verlag. The natural economic order (English translation). Peter Owen, London (1958)

Golosov M, Lucas Jr. RE (2003) Menu costs and Phillips curves. NBER Working Paper No. 10187

Goodfriend M (2000) Overcoming the zero bound on interest rate policy. J Money Credit Bank 32(4):1007-1035

Goodhart CAE (2006) Money and default. Mimeo, London School of Economics and Political Science

Hicks JR (1967) The two triads. In: Hicks JR (ed) Critical essays in monetary theory. Oxford University Press, Oxford, pp 1-60

Lucas RE (1982) Interest rates and currency prices in a two-country world. J Monet Econ 10(3):335-359

McCallum BT, Goodfriend MS (1987) Money: theoretical analysis of the demand for money. In: The new Palgrave: a dictionary of economic theory and doctrine. Macmillan, London. Federal Reserve Bank of Richmond, Econ Rev 74:16-24 (1988)

McCallum BT (1989) Monetary economics, theory and policy. Macmillan, New York

McCallum BT (2001) Monetary policy analysis in models without money. Fed Reserve Bank St. Louis Rev 83:145-160

Niehans J (1978) The theory of money. Johns Hopkins University Press, Baltimore, MD

Niepelt D (2004) The fiscal myth of the price level. Q J Econ 119(1):277-300

Patinkin D (1965) Money, interest, and prices (2nd edn). Harper \& Row, New York

Taylor JB (1980) Aggregate dynamics and staggered contracts. J Polit Econ 88:1-23 
Walsh CE (2000) Monetary theory and policy. The MIT Press, Cambridge, MA

Wikepedia (2004) The Free Encyclopedia. http://en.wikipedia.org/wiki/Mindset

Woodford M (2001) Fiscal requirements for price stability. J Money, Credit Banking 33:669-728

Woodford M (2003) Interest and prices; foundations of a theory of monetary policy. Princeton University Press, Princeton, NJ 